Mixed-Ionic and Electronic

\title{
Conductivity in Polymers
}

Annual Technical Progress Report

Grant No. DE-FG02-85F:F45220

Submitted to

The United States Department of Energy

Washington, D.C. 20545

by

M. A. Ratner and D. F. Shriver

Northwestern University

Evanston, IL 60208

\section{DISCLAIMER}

This report was prepared as an account of work sponsured by an agency of the United States Government. Neither the United States Government nor any agency thereof, nor any of their employees, makes any warranty, express or implied, or assumes any legal liability or responsibility for the accuracy, complisteness, or usefulness of any information, apparatus, product, or process disclosed, or represents that its use would not infringe privately owned right. Reference herein to any specific commercial product, process, or service by trade name, trademark, manufacturer, or otherwise does not necessarily constitute or imply its endorsement, recommendation, or favoring by the United States Government or any agency thereof. The views and opinions of authors expressed herein do noc necessarily state or reflect those of the United States Government or any agency thereof. 


\section{Summary of Progress in Current Funding Period.}

\section{A. Substituted Polypyrroles and Polythiophenes}

In the last year we succeeded in growing films from the polyether substituted pyrrole, 3,6-dioxaheptyl-pyrrole-3 acetate, which was electrodeposited on polished platinum surfaces to give smooth polymer films. These films were structurally characterized by SEM, STM, and profilometry, and electrochemically observed to undergo reversible oxidation at $0.3 \mathrm{~V}$ vs $\mathrm{Ag} / \mathrm{AgCl}$. Ion diffusion measurements, determined by ac impedance techniques on the unoxidized film, with an electrolyte consisting of $\mathrm{LiBF}_{4}$ and $\mathrm{MSO}_{3} \mathrm{CF}_{3}(\mathrm{M}=\mathrm{Li}, \mathrm{Na}, \mathrm{K})$ in tetraethyleneglycol dimethyl ether gave $\mathrm{D}_{\mathrm{app}} \approx 10^{-8} \mathrm{~cm}^{2} \mathrm{~s}^{-1}$. Ion diffusion in these films is one to two orders of magnitude greater than that for pure polypyrrole. Cyclic voltammetry indicates much faster switching time for the substituted pyrrole than simple pyrrole films, again confirming the faster ion diffusion in the oligoether substituted material.

Very recently we have grown films of similarly substituted polythiophenes. The key synthetic step in the preparation of the thiophenes was the addition of a small concentration of bithiophene in the electrochemical cell. Initial ac impedance measurements have been performed on these systems.

\section{Theorotical modeling of polymer electrolytes and mixed ionic-electronic conductors.}

Modeling and formal theoretical studies being carried out in conjunction with our experimental studies are focusing on the role of Coulomb interactions in modifying the conductivity both in pure polymer electrolytes and in polymer-based mixed conductors. The anion/cation coulomb attraction results in extensive ion pairing, which can decrease the effective carrier number and the resulting conductivity. Such trapping effects can be 
overcome by enclosing the cation in a cryptand or crown ether, as demonstrated in our 1990 Chemistry of Materials paper (Doan et. al.). Alternatively, change of charge density should modify the screening of the attractive coulomb potential, and may therefore lead to breakup of ion pairs at higher charge density (higher ionic concentration in electrolytes, more partial reduction or oxidation in mixed-conductive electrodes).

To elucidate the effects of charge density, we are carrying out two types of simulations. Monte-Carlo calculations on a simple electrolyte model have clearly demonstrated two characteristic times for the correlated ion hopping process; the first is simply the ion hopping time, while second and larger time corresponds to a relaxation of the Coulomb field around an ion, and is indeed sensitive both to temperature and to overall charge density. This suggests that the effects of pairing might well drop off with higher concentration, as has been suggested in the electrolyte literature for the past half century.

To clarify precisely how pairing effects conductivity, we are engaged in molecular dynamics study of concentrated electrolytes. We find that the effective potential of mean force (causing pairing) between cation and anion indeed does become less structured at lower temperature, lending to increased pairing at higher temperature (as has been observed experimentally). This stands in sharp contrast to other models in the electrolyte literature, and clearly shows the level of understanding that dynamics simulation can provide. The frequency-dependent conductivity obtained from these simulations provides, by comparison with experimental vibrational and microwave spectra, a direct comparison of the modeling and the laboratory materials. 


\section{Published Research}

1. M. Silverbeı, M. A. Ratner, Rony Granek, and A. Nitzan, Tracer Diffusion of Interacting Particles on Incomplete Lattices: Effective Medium Approximation, $J$. Chem. Phys., 93(5), 3420 (1990).

2. M. A. Ratner and A. Nitzan, Polymer Electrolytes: Hopping, Domain Structures and Frequency-Dependent Conductivity, Mat. Res. Soc. Symp. Proc., Vol. 210, 109 (1991).

3. M. A. Ratner, Review Article: Polymer Solid Electrolytes: Charge Transport Mechanisms, Materials Forum, 15, 1-15 (1991).

4. S. D. Druger, M. A. Ratner and A. Nitzan, Charge Carrier Mobility in Polymer materials: Mechanisms in Polymer Electrolytes, and Relationships to Electronic Conductors, Mol. Cryst. Liq. Cryst., Vol. 190, 171-183 (1990).

5. K. E. Doan, B. J. Heyen, M. A. Ratner and D. F. Shriver, Influence of Cryptands and Crown Ethers on Ion Transport and Vibrational Spectra of Polymer-Salt Complexes, Chem. Mater., 2, 539 (1990). 

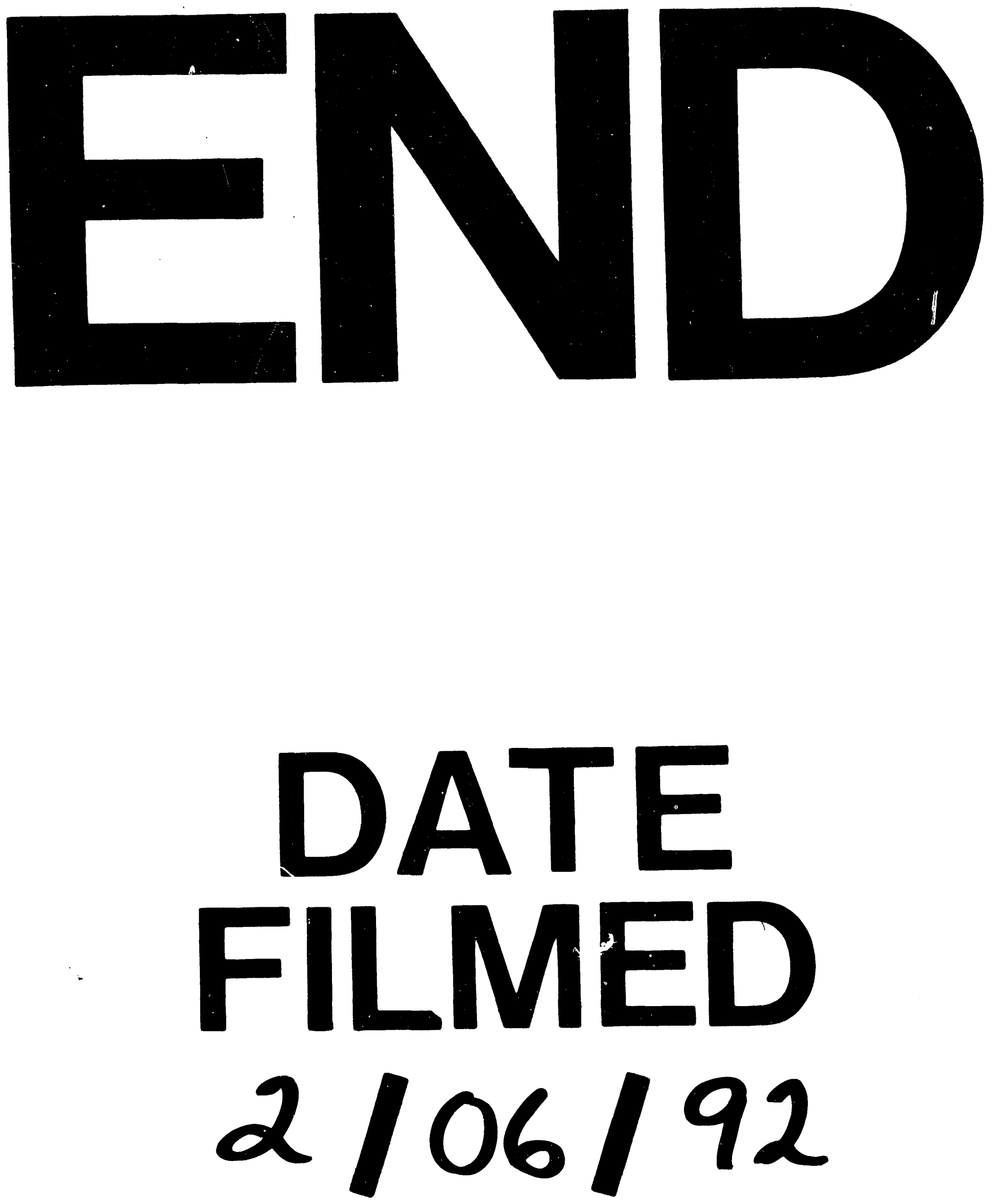

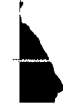


, I II 